\title{
Belinostat Regimen
}

National Cancer Institute

\section{Source}

National Cancer Institute. Belinostat Regimen. NCI Thesaurus. Code C160795.

A regimen consisting of belinostat that may be used in the treatment of relapsed or refractory peripheral T-cell lymphoma (PTCL). 